\title{
Rearing of the box tree pyralid, Glyphodes perspectalis, larvae using an artificial diet
}

\author{
Kei KAWAZU, ${ }^{1, *, \dagger}$ Suguru NAKAMURA ${ }^{2}$ and Tarô AdATI ${ }^{2}$ \\ ${ }^{1}$ Interdisciplinary Graduate School of Science and Engineering, Tokyo Institute of Technology; Midori-ku, Yokohama 226-8502, \\ Japan \\ ${ }^{2}$ Faculty of International Agriculture and Food Studies, Tokyo University of Agriculture; Setagaya-ku, Tokyo 156-8502, Japan \\ (Received 27 March 2009; Accepted 4 October 2009)
}

\begin{abstract}
Larvae of Glyphodes perspectalis were reared successfully on an artificial diet consisting of dried powder produced from box tree, Buxus microphylla, leaves and INSECTA F-II (Nihon Nosan Co., Ltd) at a ratio of 30:70. This artificial diet supported larval growth with a pupation rate of approximately $70 \%$. This rate was comparable to that on conventional rearing using fresh host plant leaves. No significant difference in the larval period, pupal period, pupal weight, pupation rate, and emergence rate was noted between the two groups. The number of eggs laid by the resultant adult females, the preoviposition period, and the hatchability of eggs were also similar regardless of the diet; however, no larvae reached the pupal stage when they were given INSECTA F-II alone. Utilization of the artificial diet facilitates the stable rearing of $G$. perspectalis throughout the year.
\end{abstract}

Key words: Glyphodes perspectalis; rearing; artificial diet; INSECTA F-II

\section{INTRODUCTION}

The box tree pyralid, Glyphodes perspectalis (Lepidoptera: Crambidae), is a pest of Buxus plants, originally distributed in Asian countries such as Japan, Korea, China, and India (Inoue, 1982; Tang et al., 1990; Zhou et al., 2005). G. perspectalis has three generations in Shanghai, China (Tang et al., 1990; Zhou et al., 2005) and in the Tokyo-Chiba district, Japan (Maruyama and Shinkaji, 1987). Recently, due to introduction of the species, damage to Buxus plants by G. perspectalis has been reported in European countries, such as Germany, The Netherlands, and Switzerland (EPPO, 2008; Krüger, 2008; Rennwald, 2008).

The severity of damage to Buxus plant species (e.g., B. microphylla, B. microphylla var. insularis, $B$. sempervirens, and B. sinica) has been markedly increasing in Japan (Uezumi, 1975; Maruyama and Shinkaji, 1987, 1991, 1993; Maruyama, 1992, 1993). In particular, G. perspectalis larvae cause severe defoliation of B. microphylla. Mature larvae feed on many leaves of Buxus plants, resulting in withering and death (Uezumi, 1975, 2003; Osaka Plant Protection Association, 2005). In Europe, Buxus plants are commonly planted in gardens, such as parterres, hedges, and topiaries. Severe attacks by $G$. perspectalis lead to defoliation and therefore completely disfigure Buxus plants which, in many cases, are grown for ornamental purposes (EPPO, 2008; Krüger, 2008; Rennwald, 2008). G. perspectalis in Europe could represent a threat to nurseries, parks, and gardens. Accordingly, studies on eradication measures have been started in Germany (EPPO, 2008; Krüger, 2008).

Since it is necessary to secure many insects throughout the year to conduct physiological research and control examinations, it is necessary to establish a rearing method using an artificial diet in order to obtain sufficient numbers of insects stably (Yushima, 1970; Wei et al., 2001; Tsuda et al., 2006). Artificial diets enable us to get synchronous individuals under various controlled conditions throughout the year (Tsuda et al., 2006). From this

\footnotetext{
* To whom correspondence should be addressed at: E-mail: kkawazu@affrc.go.jp

† Present address: National Agricultural Research Center, Kannondai 3-1-1, Tsukuba, Ibaraki 305-8666, Japan.

DOI: $10.1303 /$ aez.2010.163
} 
point of view, it is necessary to develop a simplified method to rear G. perspectalis stably using an artificial diet throughout the year.

Since a diet for phytophagous insects, INSECTA F-II, which contains no plant leaf powder and has been successfully applied, is commercially available, we initially tested this diet with and without powdered leaves of the host plant of G. perspectalis. The other Crambidae species, Cnaphalocrocis medinalis, Ostrinia palustralis, and Maruca vitrata, are reared on artificial diets (INSECTA F-II or Silkmate L4M) with powdered leaves of the host plants (Furuta et al., 1998; Ohmura et al., 2000; Chi et al., 2004; Fukuzawa et al., 2004; Tsuda et al., 2005). We considered that it is possible to stimulate feeding by $G$. perspectalis through the addition of powdered host plant leaves to the artificial diet. In the present study, we tested an artificial diet for rearing neonate instars of $G$. perspectalis, with the aim of rearing this insect without using fresh plant leaves throughout the larval stage and obtaining sufficient numbers of insects stably throughout the year.

\section{MATERIALS AND METHODS}

Insects. Adult females of $G$. perspectalis were collected from box trees, B. microphylla, at RIKEN (Saitama Pref., Japan) in 2006, and maintained in plastic cups $(290 \mathrm{~mm}$ diam. $\times 140 \mathrm{~mm}$ height $)$ with cotton soaked in 5\% honey solution as food. After allowing oviposition for $3 \mathrm{~d}$, neonates from the eggs laid on the surface of the cup were used in the experiments. The insects were reared at $25^{\circ} \mathrm{C}$ with a $60 \%$ R.H. and $16 \mathrm{~L} 8 \mathrm{D}$ photoperiod throughout the experiment.

Artificial diets. INSECTA F-II (a diet for phytophagous insects, dry formula, without plant leaf powder) was purchased from Nihon Nosan Co. (Yokohama, Japan). We selected a commercial diet without plant leaf powder because we considered the possibility that mulberry leaf powder in other commercial diets inhibited feeding by G. perspectalis larvae. Host plant powder was prepared in the laboratory; leaves of the box tree, B. microphylla, were dried at $70^{\circ} \mathrm{C}$ for $1 \mathrm{~h}$ and powdered using an electric blender. In a stainless steel container $(14 \times 20 \times 7.5 \mathrm{~cm}), 1) 250 \mathrm{~g}$ INSECTA F-II alone or 2) mixture of $175 \mathrm{~g}$ INSECTA F-II plus $75 \mathrm{~g}$ host plant powder were weighed. The ratio $(70: 30)$ of
INSECTA F-II and the powdered leaves of host plants was based on the reports of Aedia leucomelas (Tsuda et al., 2006), C. medinalis (Ohmura et al., 2000; Tsuda et al., 2005) and M. vitrata (Chi et al., 2004). After the addition of $750 \mathrm{ml}$ hot water and mixing, the diet was steamed for $1 \mathrm{~h}$. After cooling, the diet was then kept in a refrigerator until use.

Rearing experiments. Newly hatched larvae were employed in the rearing experiments. Using a small soft brush, hatching larvae were placed on the host plant leaf or a piece of artificial diet $(20 \times 20 \mathrm{~mm}$; thickness $5 \mathrm{~mm})$ in individual plastic cups $(115 \mathrm{~mm}$ upper diam. $\times 64.4 \mathrm{~mm}$ lower diam. $\times 74 \mathrm{~mm}$ height). The slices of artificial diet or fresh box tree leaves were replenished twice a week. Larval growth on the artificial diet (mixture of $175 \mathrm{~g}$ INSECTA F-II plus $75 \mathrm{~g}$ host plant powder) was compared with that on box tree leaves. The cocoon was removed from the plastic cup. The larva was removed from the cocoon, and pupation was observed. Furthermore, hatched larvae were reared on INSECTA F-II with a host plant leaf supplement from 2-day-old second instar to 1-day-old fourth instar and, thereafter, INSECTA F-II alone was added. The efficiency of these artificial diets and box tree leaves was assessed by recording pupae and adult yields, larval and pupal periods, and pupal weight.

Mating and oviposition experiments. In a screen cage $(32 \times 22 \times 30 \mathrm{~cm})$, three or four pairs of 1 -day-old adults were allowed to mate for $2 \mathrm{~d}$. Mating behavior was observed at 30-min intervals during the scotophase. Mated pairs were removed from the cage and housed in a plastic cup. Mated female moths were then individually housed in plastic cups $(290 \mathrm{~mm}$ diam. $\times 140 \mathrm{~mm}$ height $)$ with cotton soaked in a $5 \%$ honey solution to allow them to lay eggs. The number of eggs laid on the surface of the cup was counted. The efficiency of the artificial diet and box tree leaves was assessed by recording the mating rate, total eggs, preoviposition period, and hatchability. The preoviposition period was defined as the period from emergence to oviposition.

Rearing for successive generations. We investigated pupae yields and the number of eggs laid by females reared using the artificial diet for four generations.

Statistical analysis. The differences in the larval 
period, pupal period, and pupal weight for each treatment were tested for significance by the $t$-test. Variations in the pupation rate and emergence for each treatment were tested for significance by Tukey-type multiple comparisons for the proportions test. Data for the survival days of larvae after switching from the mixture of INSECTA F-II plus host plant powder to INSECTA F-II alone were fitted to the Weibull distribution and analyzed using parametric survival analysis. Pairwise comparisons of the survival days of larvae after switching from the mixture of INSECTA F-II plus host plant powder to INSECTA F-II alone were determined using the log-rank test of the Kaplan-Meier method with Holm adjustment. Differences in the preoviposition period, numbers of eggs laid by females and the hatchability of eggs with each treatment were tested for significance by the $t$-test. Differences in the numbers of eggs laid by females each generation were tested for significance by one-way ANOVA.

\section{RESULTS AND DISCUSSION}

Yields at each stage with the two different diets are shown in Table 1. The pupation rates on the artificial diet and host plant leaves were 66 and $70 \%$, respectively (Table 1), while no hatched larvae reached the pupal stage when they were given INSECTA F-II alone. All hatched larvae raised on INSECTA F-II alone died during the first $6 \mathrm{~d}$. Feeding of hatched larvae on INSECTA F-II was not observed. Hatched larvae were not reared on INSECTA F-II alone, but on INSECTA F-II with $B$. microphylla powder; therefore, $G$. perspectalis hatched larvae appear to require the presence of a feeding stimulant in the host plant, B. microphylla. For O. palustralis (Fukuzawa et al., 2004) and $C$. medinalis (Furuta et al., 1998), early instars of $O$. palustralis larvae do not feed on Silkmate L4M alone, and early instars of $C$. medinalis larvae do not feed on INSECTA F-II alone, but on the artificial diet with powdered host plant leaves. However, later instars of $O$. palustralis and $C$. medinalis larvae can feed on the artificial diet alone without powdered host plant leaves, and show complete larval development. These reports suggest that $O$. palustralis and $C$. medinalis larvae lose the requirement for a feeding stimulant during larval development. The survival days of $G$. perspectalis

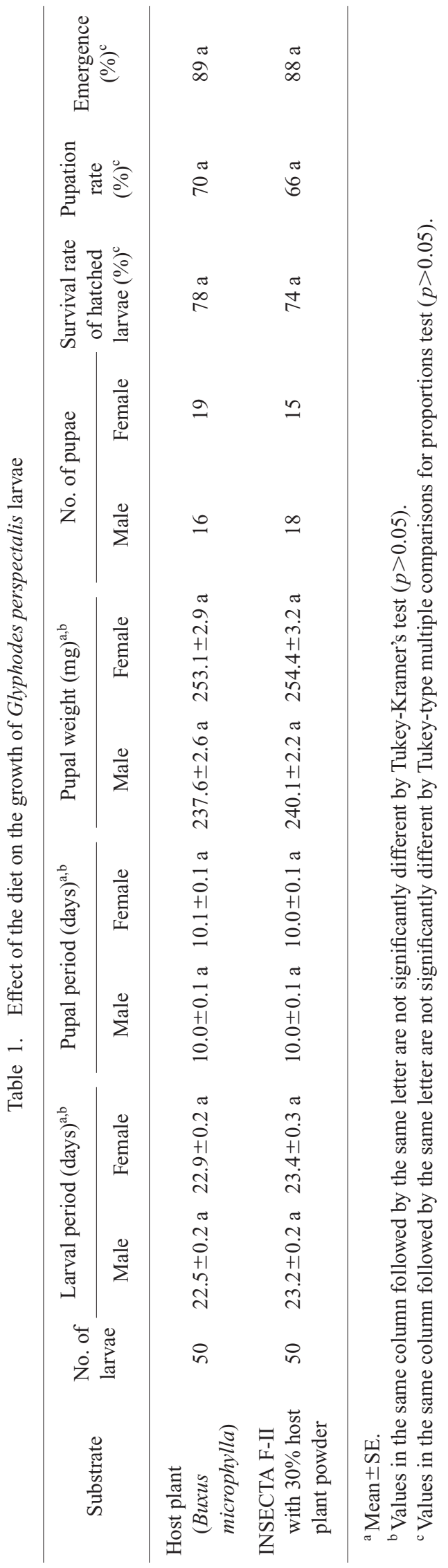


larvae after switching from the mixture of INSECTA F-II plus host plant powder to INSECTA F-II alone at fourth instar were significantly longer than at second instar (Table 2). However, no $G$. perspectalis larvae at young instars (first-fourth instar) can develop on INSECTA F-II alone, and no individuals will complete larval development (Table 2). Our results suggest that $G$. perspectalis larvae at young instars (first-fourth instar) also require the feeding stimulant present in the host plant. It also appears that the feeding stimulant in $B$. microphylla retains stability against drying and heating, because it can be incorporated into the artificial diet in the form of dried leaf powder. The survival rates of hatched larvae on the artificial diet and host plant leaves were 74 and $78 \%$, respectively, while adult emergence rates as a percentage of the number of pupae on the artificial diet and host plant leaves were 88 and $89 \%$, respectively (Table 1). From these results, it seems that the yield of adults from eggs depends greatly on the survival of larvae, particularly of young instars, but not on that of pupae. It is therefore necessary to

Table 2. Survival days of G. perspectalis larvae after switching from the mixture of INSECTA F-II plus host plant powder to INSECTA F-II alone

\begin{tabular}{ccc}
\hline \multicolumn{1}{c}{$\begin{array}{c}\text { Days after } \\
\text { molting }\end{array}$} & $\begin{array}{c}\text { No. of } \\
\text { larvae }\end{array}$ & $\begin{array}{c}\text { Survival days } \\
\text { of larvae }{ }^{\mathrm{b}, \mathrm{c}}\end{array}$ \\
\hline 2-day-old 2nd instar (5) & 50 & $4.4 \pm 0.2 \mathrm{a}$ \\
0-day-old 3rd instar (6) & 50 & $4.8 \pm 0.2 \mathrm{ab}$ \\
1-day-old 3rd instar (7) & 50 & $4.9 \pm 0.2 \mathrm{ab}$ \\
2-day-old 3rd instar (8) & 50 & $4.9 \pm 0.2 \mathrm{ab}$ \\
0-day-old 4th instar (9) & 50 & $5.4 \pm 0.2 \mathrm{bc}$ \\
1-day-old 4th instar (10) & 50 & $5.7 \pm 0.2 \mathrm{bc}$ \\
\hline
\end{tabular}

${ }^{a}$ Days after hatching are shown in parentheses.

${ }^{\mathrm{b}}$ Mean \pm SE.

${ }^{c}$ Values with the same letter are not significantly different by parametric survival analysis. maximize the survival of larvae by improving the artificial diet.

Male and female growth periods from larval hatching to adult emergence on the artificial diet were 33.2 and $33.4 \mathrm{~d}$, respectively. Periods on host plant leaves were 32.5 and $33.0 \mathrm{~d}$, respectively. From these results, the growth period from larval hatching to adult emergence on the artificial diet took the same length of time as that on host plant leaves. The mean weights of male and female pupae on the artificial diet were 240.1 and $254.4 \mathrm{mg}$, respectively, while those on host plant leaves were 237.6 and $253.1 \mathrm{mg}$, respectively. No significant difference in the larval period, pupal period, pupal weight, pupation rate, and emergence rate was noted between the two groups (Table 1), and no deformity of adult moths reared on the artificial diet was observed. The larval period, pupal period, and mean weight of pupae on the artificial diet in the present study were similar to those on host plant leaves in B. microphylla, reported by Maruyama and Shinkaji (1991).

The number of eggs laid by females, the preoviposition period in adult females, and the hatchability of larvae reared on the artificial diet and host plant leaves were also examined (Table 3). Almost all females mated within $2 \mathrm{~d}$ irrespective of the diet on which larvae were reared. The mating rates of adult moths derived from larvae reared on the artificial diet and host plant leaves were 93 and 94\%, respectively. The number of eggs laid by females on the artificial diet and host plant leaves were 361.4 and 392.4, respectively. The hatchability of eggs laid by females on the artificial diet and host plant leaves was 77.1 and $79.7 \%$, respectively. The preoviposition periods on the artificial diet and host plant leaves were 4.2 and $3.8 \mathrm{~d}$, respectively. The number of eggs laid, the preoviposition period, and hatchability of eggs laid did not significantly differ

Table 3. Effect of larval diet on the reproduction of $G$. perspectalis females

\begin{tabular}{cccccc}
\hline Substrate & $\begin{array}{c}\text { No. of adult } \\
\text { females }\end{array}$ & $\begin{array}{c}\text { Mating rate } \\
(\%)\end{array}$ & $\begin{array}{c}\text { Preoviposition period } \\
(\mathrm{d})^{\mathrm{a} . \mathrm{b}}\end{array}$ & $\begin{array}{c}\text { No. of eggs/ } \\
\text { female }^{\mathrm{a} . \mathrm{b}}\end{array}$ & $\begin{array}{c}\text { Hatchability } \\
(\%)\end{array}$ \\
\hline $\begin{array}{l}\text { Host plant } \\
\text { INSECTA F-II } \\
\text { with 30\% host } \\
\text { plant powder }\end{array}$ & 17 & 94 & $3.8 \pm 0.2 \mathrm{a}$ & $392.4 \pm 46.7 \mathrm{a}$ & $79.7 \pm 2.1 \mathrm{a}$ \\
\hline
\end{tabular}

\footnotetext{
${ }^{\mathrm{a}} \mathrm{Mean} \pm \mathrm{SE}$.

${ }^{\mathrm{b}}$ Values in the same column followed by the same letter are not significantly different by Tukey-Kramer's test $(p>0.05)$.
} 
Table 4. Pupal yields and total eggs of $G$. perspectalis at each generation on rearing for successive generations on the artificial diet

\begin{tabular}{|c|c|c|c|c|c|}
\hline \multirow{2}{*}{ Generation } & \multirow{2}{*}{ No. of larvae } & \multicolumn{2}{|c|}{ No. of pupae } & \multirow{2}{*}{ Pupation rate $(\%)^{\mathrm{a}}$} & \multirow{2}{*}{$\begin{array}{l}\text { No. of eggs/ } \\
\text { female }^{\mathrm{b}, \mathrm{c}}\end{array}$} \\
\hline & & Male & Female & & \\
\hline 2 & 50 & 20 & 16 & $72 \mathrm{a}$ & $340.6 \pm 52.1 \mathrm{a}$ \\
\hline 3 & 50 & 18 & 14 & $64 \mathrm{a}$ & $293.7 \pm 44.1 \mathrm{a}$ \\
\hline 4 & 50 & 20 & 15 & $70 \mathrm{a}$ & $273.6 \pm 23.3 \mathrm{a}$ \\
\hline
\end{tabular}

${ }^{a}$ Values in the same column followed by the same letter are not significantly different by the Tukey-type multiple comparisons for proportions test $(p>0.05)$.

${ }^{\mathrm{b}}$ Mean \pm SE.

${ }^{c}$ Values in the same column followed by the same letter are not significantly different by one-way ANOVA $(p>0.05)$.

between the two groups of females (Table 3). The number of eggs laid by females on this artificial diet in the present study was not so different from those on B. microphylla leaves in the previous report by Maruyama and Shinkaji (1987).

The yield in each generation on rearing for successive generations on the artificial diet is shown in Table 4. The pupal yield and eggs laid did not differ among generations. From these experimental results, it can be concluded that we successfully reared more than four generations using the artificial diets for larvae.

The present study shows that the artificial diet can be a substitute for host plant leaves in the conventional rearing of $G$. perspectalis. Our method allows the synchronous collection of pupae. Adults eclose normally, and the colony thrived on the artificial diet with host plant leaf powder for more than four generations. The results presented here show that it is possible to rear G. perspectalis throughout the year in the laboratory.

\section{ACKNOWLEDGMENTS}

We express our thanks to Ms N. Mitsuzawa and the students of Tokyo University of Agriculture for rearing insects. We thank Professor Hiroshi Honda of the University of Tsukuba and Professor Sadahiro Tatsuki of the University of Tokyo for the critical review of the manuscript. This study was supported in part by a Matching Fund Subsidy for Private Universities as an "Academic Frontier" Project from the Japanese Ministry of Education, Culture, Sports, Science and Technology to Tokyo University of Agriculture.

\section{REFERENCES}

Chi, Y., Y. Sakamaki, K. Tsuda and K. Kusigemati (2004) Simple artificial diets for mass-reproduction of the legume pod borer, Maruca vitrata (Lepidoptera: Cram- bidae). Jpn. J. Appl. Entomol. Zool. 48: 315-320 (in Japanese with English summary).

EPPO (European and Mediterranean Plant Protection Organization) (2008) PQR database. European and Mediterranean Plant Protection Organization, Paris, France. www.eppo.org/

Fukuzawa, M., S. Tatsuki and Y. Ishikawa (2004) Rearing of Ostrinia palustralis (Lepidoptera: Crambidae) larvae with a switchover of two kinds of artificial diets. Appl. Entomol. Zool. 39: 363-366.

Furuta, T., H. Kamiwada and K. Kusigemati (1998) Rearing of the rice leaffolder, Cnaphalocrocis medinalis Guenée (Lepidoptera: Pyralidae), on an artificial diet. Kyushu Pl. Prot. Res. 44: 41-44 (in Japanese).

Inoue, H. (1982) In Moths of Japan. Vol. 1 (H. Inoue, S. Sugi, H. Kuroko, S. Moriuti, A. Kawabe and M. Owada, eds.). Kodansha, Tokyo, p. 346 (in Japanese).

Krüger, E. O. (2008) Glyphodes perspectalis (Walker, 1859) — neu fur die Fauna Europas (Lepidoptera: Crambidae). Entomol. Z. 118: 81-83.

Maruyama, T. (1992) Difference in injury levels caused by the box tree pyralid, Glyphodes perspectalis (Walker) (Lepidoptera: Pyralidae) on various box-trees. Jpn. J. Appl. Entomol. Zool. 36: 56-58 (in Japanese with English summary).

Maruyama, T. (1993) Life cycle of the box-tree pyralid, Glyphodes perspectalis (Walker) (Lepidoptera: Pyralidae). IV. Effect of various host plants on larval growth and food utilization. Jpn. J. Appl. Entomol. Zool. 37: 117-122 (in Japanese with English summary).

Maruyama, T. and N. Shinkaji (1987) Studies on the life cycle of the box-tree pyralid, Glyphodes perspectalis (Walker) (Lepidoptera: Pyralidae). I. Seasonal adult emergence and developmental velocity. Jpn. J. Appl. Entomol. Zool. 31: 226-232 (in Japanese with English summary).

Maruyama, T. and N. Shinkaji (1991) The Life cycle of the box-tree pyralid, Glyphodes perspectalis (Walker) (Lepidoptera: Pyralidae). II. Developmental characteristics of larvae. Jpn. J. Appl. Entomol. Zool. 35: 221-230 (in Japanese with English summary).

Maruyama, T. and N. Shinkaji (1993) The life cycle of the 
box-tree pyralid, Glyphodes perspectalis (Walker) (Lepidoptera: Pyralidae). III. Photoperiodic induction of larval diapause. Jpn. J. Appl. Entomol. Zool. 37: 45-51 (in Japanese with English summary).

Ohmura, H., K. Tsuda, H. Kamiwada and K. Kusigemati (2000) Rearing of rice leaffolder, Cnaphalocrocis medinalis (Guenée) (Lepidoptera: Pyralidae), on artificial diets. Jpn. J. Appl. Entomol. Zool. 44: 119-123 (in Japanese with English summary).

Osaka Plant Protection Association (2005) An Illustrated Guide to Horticultural Pests in Osaka Prefecture. Available from http://www.epcc.pref.osaka.jp/afr/zukan/055. htm

Rennwald, R. (2008) Bestimmungshilfe für die in Europa nachgewiesenen Schmetterlingsarten. Available from http:// www.lepiforum.eu/cgi-bin/lepiwiki.pl?action = browse \& id=Glyphodes_Perspectalis

Tang, S. J., H. Z. Qin and W. Sun (1990) Studies on bionomics of Diaphania perspectalis. J. Shanghai Agr. Col. 8: 307-312.

Tsuda, K., H. Ohmura, Y. Sakamaki, H. Kamiwada and K. Kusigemati (2005) Mass rearing of the rice leaffolder, Cnaphalocrocis medinalis (Guenée) (Lepidoptera: Pyrali- dae), on an artificial diet. Jpn. J. Appl. Entomol. Zool. 49: 215-221 (in Japanese with English summary).

Tsuda, K., S. Higashino, Y. Sakamaki and H. Inoue (2006) Rearing of sweet potato leaf warm, Aedia leucomelas Linné, on an artificial diet. Mem. Fac. Agr. Kagoshima Univ. 56: 39-44 (in Japanese with English summary).

Uezumi, Y. (1975) Lepidoptera harmed the trees and the pest control. Plant Prot. 29: 349-354 (in Japanese).

Uezumi, Y. (2003) In Agricultural Insect Pests in Japan (K. Umeya and T. Okada, eds.). Zenkoku Noson Kyoiku Kyokai, Tokyo, p. 856 (in Japanese).

Wei, B., H. Sakurai and K. Tsuchida (2001) Artificial diets for the alfalfa weevil, Hypera postica. Jpn. J. Appl. Entomol. Zool. 45: 117-121 (in Japanese with English summary).

Yushima, K. (1970) Massing-rearing of insects and its application to pest control. Agr. Hort. 45: 1631-1636 (in Japanese).

Zhou, W., C. Y. Xia, X. Q. Sun, B. Zhu, X. P. Liu, Z. C. Liu and Y. Wang (2005) Studies on the biological characteristics and control of Diaphania perspectalis Walker. J. Shanghai Jiaotong Univ. Agr. Sci. 23: 52-56. 